\title{
BIOMASSA DAN KEANEKARAGAMAN IKAN DI PERAIRAN ANCOL, TELUK JAKARTA
}

\author{
Karsono Wagiyo ${ }^{*}$ dan Sri Turni Hartati ${ }^{*}$ \\ *) Peneliti pada Balai Riset Perikanan Laut, Muara Baru-Jakarta
}

\begin{abstract}
ABSTRAK
Dampak reklamasi pantai di Ancol menghasilkan lingkungan yang tampak lebih bersih indah dan asri. Keadaan ini belum tentu diikuti peningkatan fungsional kondisi perairan dalam mendukung sumber daya perikanan, sehingga perlu diketahui kondisi sumber daya perikanan. Hasil observasi dengan menggunakan jaring bondet untuk menilai indikator kondisi sumber daya perikanan didapatkan; komposisi jenis ikan yang dominan adalah ikan Leiognathus bindus (36,68\%), diikuti Apogon sp. $(22,92 \%)$, Triacanthus brevirostris $(14,04 \%)$, Sphyraena barracuda $(10,82 \%)$, biomassa rata-rata 0,0064 $\mathrm{kg} \mathrm{m}^{-2}$ setara dengan hasil tangkapan per tawur $9,0045 \mathrm{~kg}$, indeks keanekaragaman rata-rata 1,13 dengan ukuran ikan yang tertangkap relatif kecil. Berdasarkan pada hasil ini dapat disimpulkan bahwa perairan Ancol mendukung kehidupan ikan dan merupakan tempat asuhan beberapa ikan, tetapi kondisi tidak optimum.
\end{abstract}

KATA KUNCI: keanekaragaman ikan, lingkungan, Teluk Jakarta

\section{PENDAHULUAN}

Perairan Ancol adalah bagian dari ekosistem Teluk Jakarta yang terletak antara pelabuhan Muara Baru dan pelabuhan Tanjung Priuk. Berbagai kegiatan di sekitar Ancol dapat memberi dampak positif dan negatif bagi lingkungan di sekitar. Dampak positif adalah tumbuh vegetasi pantai yang rimbun, baik mangrove maupun non mangrove (Gambar 1). Kegiatan yang dapat menimbulkan dampak negatif adalah masuk massa air yang kotor dari sungai maupun saluran pembuangan lain yang dapat menyebabkan pencemaran di daerah tersebut.

Secara visual, perairan di sekitar Ancol cukup bersih dibandingkan keadaan perairan pantai lain di Teluk Jakarta. Khusus dari segi perikanan, keadaan yang bersih secara fisik belum tentu diikuti keadaan yang baik secara fungsional.

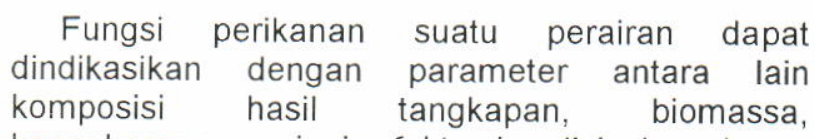
keanekaragaman jenis, faktor kondisi, dan ukuran ikan yang tertangkap. Nilai parameter tersebut dapat diperoleh dari pengambilan contoh penangkapan dengan berbagai alat tangkap yang bersifat non selektif. Tulisan ini bertujuan untuk mengetahui fungsi perairan Ancol dari segi perikanan berdasarkan pada hasil tangkapan jaring bondet (boat seine net).

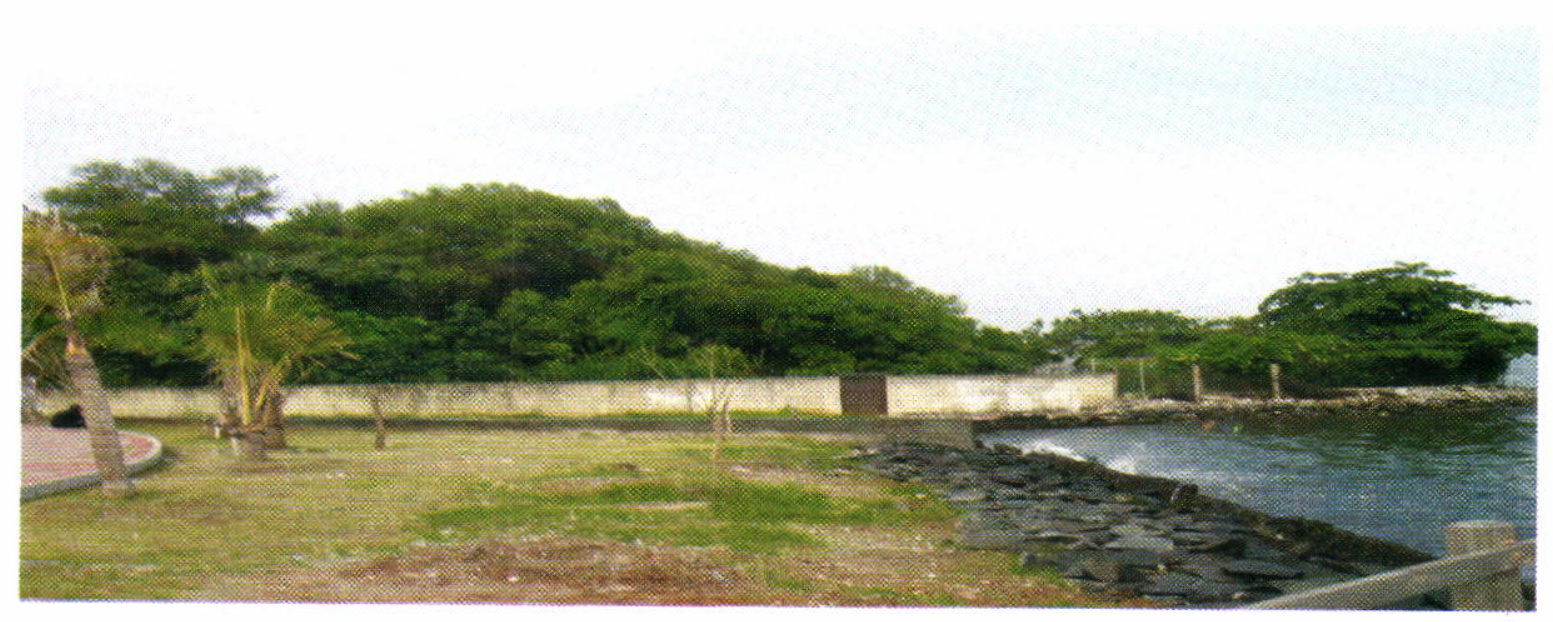

Gambar 1. Vegetasi di sekitar Pantai Ancol. 


\section{KOMPOSISI HASIL TANGKAPAN}

Pengambilan contoh dengan bondet di perairan Ancol pada bulan Oktober 2004, diperoleh 20 jenis ikan (Tabel 1). Komposisi hasil tangkapan berdasarkan pada persentase bobot, secara berurutan didominasi oleh Leiognathus bindus (36,68\%), diikuti Apogon sp. (22,92\%), Triacanthus brevirostris $(14,04 \%)$ ), Sphyraena barracuda $(10,82 \%)$, dan Sardinella fimbriata $(7,61 \%)$. Dominasi jumlah individu yang tertangkap dominan berturut-turut Apogon sp. (51,28\%), Leiognathus bindus $(36,59 \%)$, L. splendens $(4,61 \%)$, dan Triacanthus brevirostris (3,06\%).

Melihat 20 jenis ikan yang tertangkap pada umumnya adalah ikan yang mampu hidup pada perairan yang relatif buruk. Ikan yang dominan dan membutuhkan perairan relatif bersih adalah Triacanthus brevirostri dan Sphyraena barracuda. Sumber daya ikan lain, yang relatif membutuhkan perairan bersih tetapi tidak dominan adalah Sepiidae (sotong) dan Soleidae (ikan sebelah).

Tabel 1. Komposisi jenis ikan hasil tangkapan jaring bondet di perairan Ancol, bulan Oktober 2004

\begin{tabular}{lcccc}
\hline \multicolumn{1}{c}{ Jenis ikan } & Bobot contoh $\mathbf{g r}$ ) & \% bobot & Jumlah & \% ekor \\
\hline Apogon sp. & 1.790 & 22,92 & 1023 & 51,28 \\
Gerres sp. & 14 & 0,18 & 2 & 0,10 \\
Gobyoides sp. & 15 & 0,19 & 2 & 0,10 \\
Leiognathus splendens & 310 & 3,97 & 92 & 4,61 \\
L. bindus & 2.864 & 36,68 & 730 & 36,59 \\
Metapenaeus sp. & 2 & 0,03 & 1 & 0,05 \\
Mysid & 1 & 0,01 & 5 & 0,25 \\
Penaeus sp. & 3 & 0,04 & 2 & 0,10 \\
Pomadasys sp. & 10 & 0,13 & 1 & 0,05 \\
Portunus sp. & 7 & 0,09 & 2 & 0,10 \\
Sardinella fimbriata & 594 & 7,61 & 38 & 1,90 \\
Saurida sp. & 27 & 0,35 & 2 & 0,10 \\
Scienids & 4 & 0,05 & 2 & 0,10 \\
Selaroides sp. & 50 & 0,64 & 4 & 0,20 \\
Sepiidae & 138 & 1,77 & 4 & 0,20 \\
Soleidae & 18 & 0,23 & 2 & 0,10 \\
Sphyraena barracuda & 845 & 10,82 & 1 & 0,05 \\
Stetojulis sp. & 13 & 0,16 & 3 & 0,15 \\
Stoleporus sp. & 8 & 0,10 & 18 & 0,90 \\
Triacanthus brevirostris & 1.096 & 14,04 & 61 & 3,06 \\
\hline
\end{tabular}

\section{ILLUSTRASI IKAN DOMINAN}

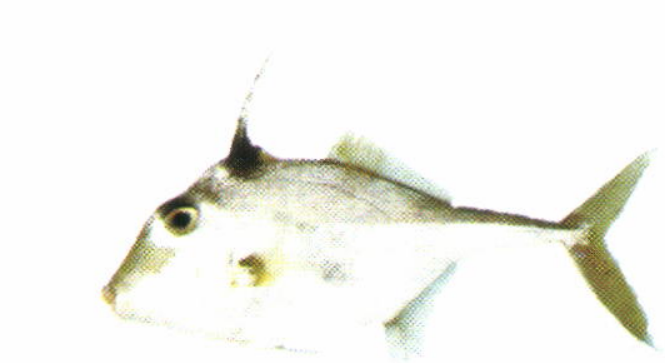

Gambar 2. Ikan sokang Tripod Fish Triachantus brevirostris

Panjang maksimal 25 sampai dengan $30 \mathrm{~cm}$. Banyak ditemukan pada perairan pantai sampai dengan kedalaman $20 \mathrm{~m}$ dan estuarin. Tertangkap dengan jaring insang, trawl, dan pancing. Daging lezat, dikonsumsi dalam bentuk segar, dan asin.

\section{Gambar 3}

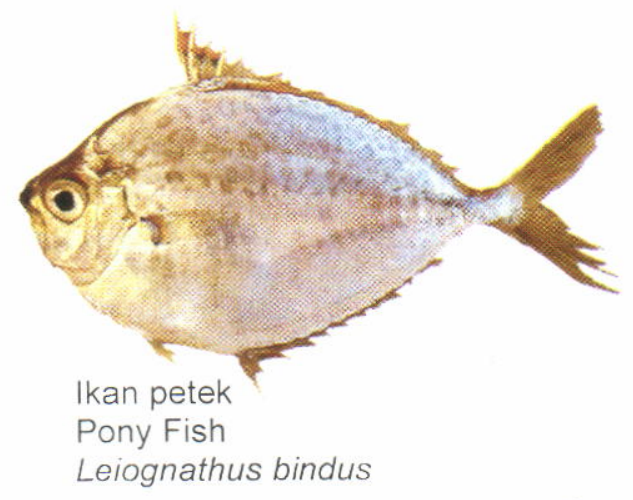

Panjang maksimum $11 \mathrm{~cm}$. Hidup pada perairan dangkal, banyak ditemukan pada kedalaman antara 20 sampai dengan $25 \mathrm{~m}$ dengan dasar berlumpur dan berpasir. Makanan utama krustasea kecil, gastropoda, bivalva, polychaeta, dan nematoda. Dikonsumsi dalam bentuk segar, asin, dan tepung ikan. Tertangkap dengan trawl dasar, jaring insang, dan pancing. 


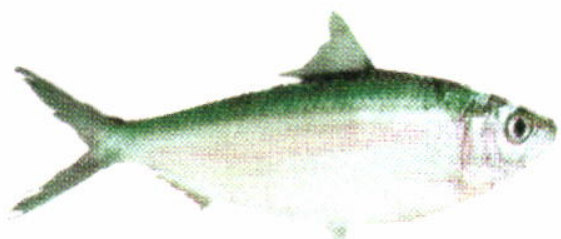

Gambar 4. Ikan tembang

Sardines

Sardinella fimbriata

Panjang maksimal $13 \mathrm{~cm}$. Bersifat pelagis pada perairan dangkal terutama pada kedalaman $25 \mathrm{~m}$. Tertangkap dengan jaring insang dan jaring angkat. Dikonsumsi dalam bentuk segar dan asin. Makanan utama berupa plankton.

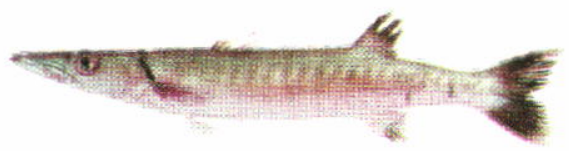

Gambar 5. Ikan alu-alu

Barracudas

Sphyraena barracuda

Panjang maksimal $180 \mathrm{~cm}$. Bersifat pelagis neritik, dekat dengan dasar, pada tingkat juvenile pada perairan dangkal dan estuarin. Konsumer yang bersifat predator. Tertangkap dengan trawl dasar, jaring insang hanyut. Dikonsumsi dalam bentuk segar, beku, dan asin.

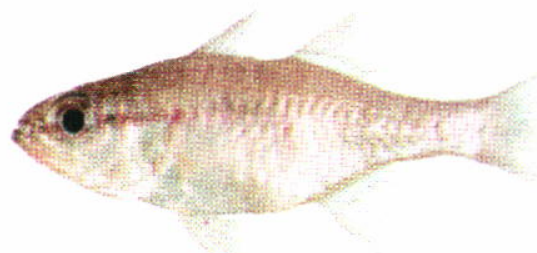

Gambar 6. Ikan beseng-beseng Cardinal Fish Apogon sp.

Pada umumnya lebih kecil dari $12 \mathrm{~cm}$. Bersifat bentik pada perairan dangkal. Tertangkap dengan trawl dan jaring angkat. Digunakan untuk hiasan akuarium, tepung ikan, dan segar sebagai pakan ternak

\section{BIOMASSA DAN KEANEKARAGAMAN JENIS}

Perhitungan biomassa didasarkan pada asumsi bahwa ikan yang ada di dalam tutupan lingkaran jaring tertangkap semua. Pada 4 kali percobaan penangkapan diperoleh biomassa terkecil yaitu $0,0001 \mathrm{~kg} \mathrm{~m}^{-2}$ setara dengan hasil tangkapan per tawur $0,1407 \mathrm{~kg}$, biomassa terbesar yaitu 0,0157 $\mathrm{kg} \mathrm{m}^{-2}$ setara dengan hasil tangkapan per tawur
$22,0892 \mathrm{~kg}$ dan biomassa rata-rata $0,0064 \mathrm{~kg} \mathrm{~m}^{-2}$ setara dengan hasil tangkapan per tawur 9,0045 $\mathrm{kg}$. Perhitungan indeks keanekaragaman ikan hasil tangkapan dengan Shannon-Wiener's, diperoleh nilai tertinggi 1,83 dan terendah 0,67 dengan ratarata 1,13 . Keanekaragaman ikan termasuk dalam kategori rendah. Nilai keanekaragaman tersebut menunjukkan bahwa perairan di sekitar Ancol mengalami pencemaran di bawah ambang batas (khronis) bagi peruntukkan kehidupan ikan.

Luas lahan penangkapan dengan jaring bondet dihitung dengan asumsi bahwa lahan yang diliput berbentuk lingkaran, sehingga diperoleh nilai $1362,85 \mathrm{~m}^{2}$. Jaring bondet yang dipergunakan mempunyai panjang 2 sayap $(2 \times 60 \mathrm{~m})$ dan diameter mulut kantong $5 \mathrm{~m}$. Penangkapan ikan dengan jaring bondet di perairan Ancol dikemukan pada

Gambar 7 .

\section{UKURAN IKAN}

Pengamatan biologi khusus panjang dan bobot ikan dilakukan pada hasil tangkapan dominan yaitu ikan Leiognathus bindus dan Triachantus brevirostris.

\section{L. bindus}

Pengamatan terhadap sebaran panjang ikan yang tertangkap dengan jaring bondet diperoleh panjang cagak rata-rata $5,3 \mathrm{~cm}$, modus antara 4,6 sampai dengan $5,0 \mathrm{~cm}$, panjang terkecil $2,6 \mathrm{~cm}$. dan terbesar $8,5 \mathrm{~cm}$. Hasil ini menunjukkan terdapat 2 kelompok umur yaitu pada panjang antara 4,6 sampai dengan $5,0 \mathrm{~cm}$ dan 7,1 sampai dengan $7,5 \mathrm{~cm}$ (Gambar 8). Ukuran yang relatif kecil mengindikasikan bahwa lokasi tempat pengambilan contoh merupakan daerah asuhan.

Pengamatan hubungan panjang bobot $L$ bindus mempunyai pertumbuhan yang allometrik positif dengan koefisien korelasi R=0,949789 (Gambar 9). Faktor kondisi (kegemukan) L. bindus pada tempat pengambilan contoh, yang terkecil 1,1 dan terbesar 1,34 dengan rata-rata 1,21. Berdasarkan pada kisaran nilai faktor kondisi, yang terkecil sama dengan 1 dan yang terbesar sama dengan 3, maka pertumbuhan L. bindus di perairan Ancol kurang baik.

\section{Triachantus brevirostris}

Berbeda dengan $L$. bindus, bahwa $T$. brevirostris menunjukkan sebaran frekuensi panjang cagak dalam 1 kelompok umur. Ukuran panjang terkecil terdapat pada kisaran antara 9,1 sampai dengan $10 \mathrm{~cm}$ dan terbesar pada kisaran 


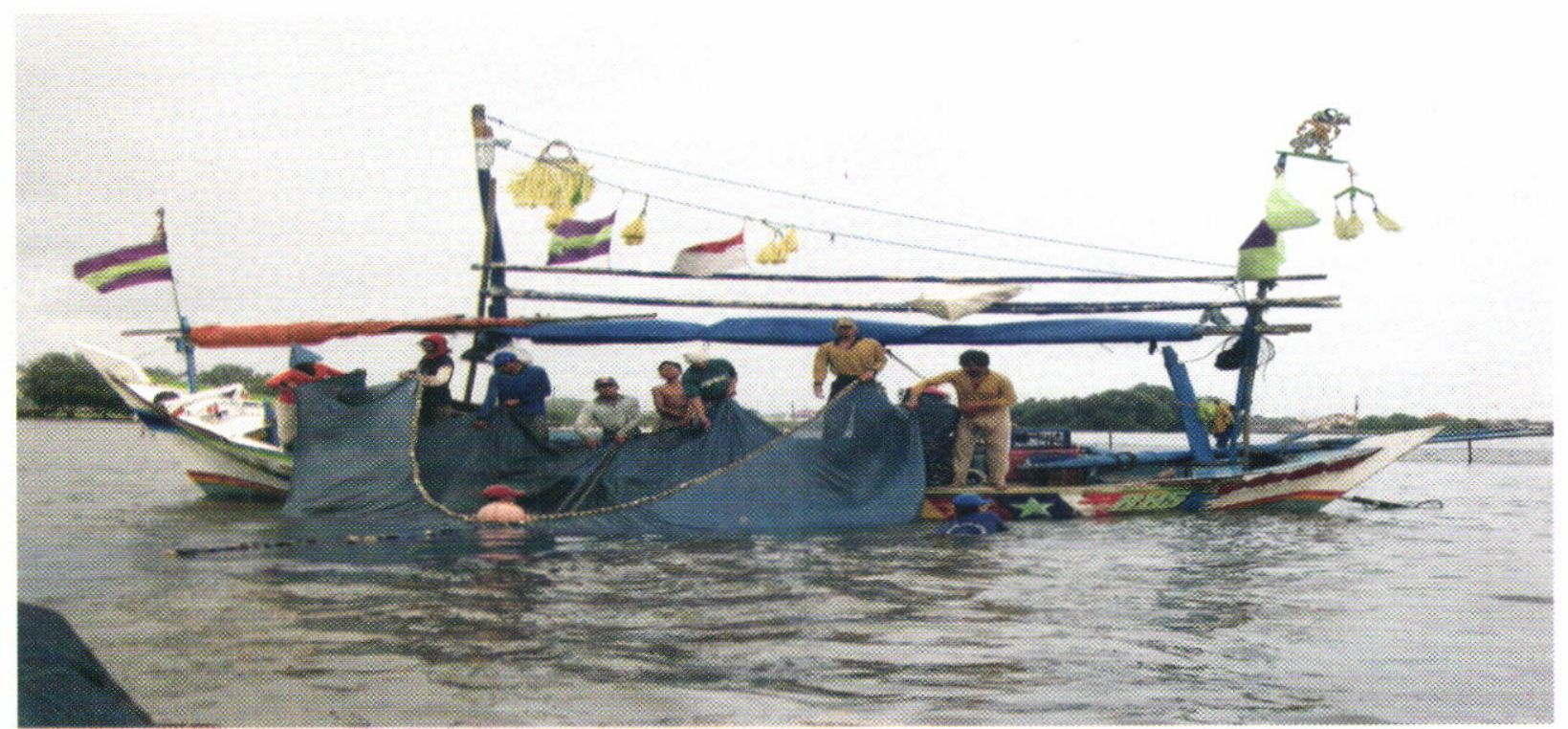

Gambar 7. Penangkapan ikan dengan jaring bondet.

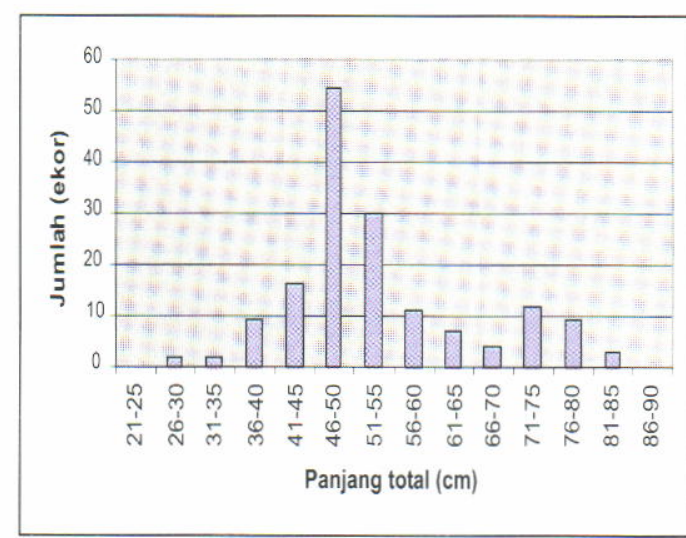

Gambar 8. $\quad$ Frekuensi ukuran L. bindus.

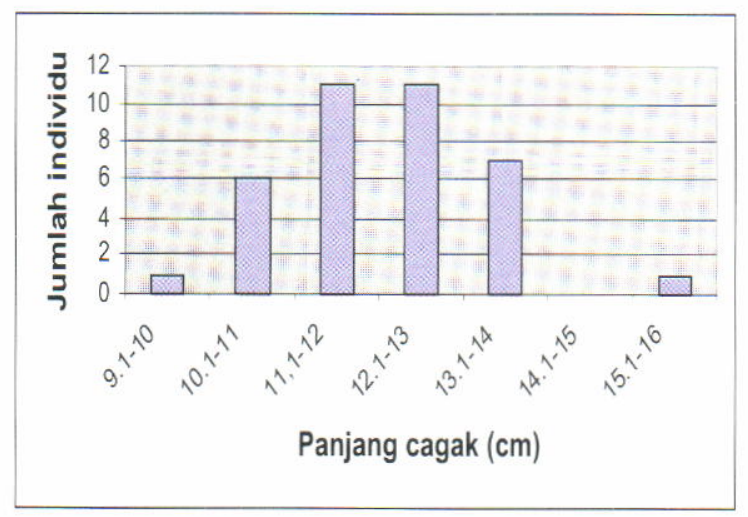

Gambar 10. Sebaran panjang cagak T. brevirostris.

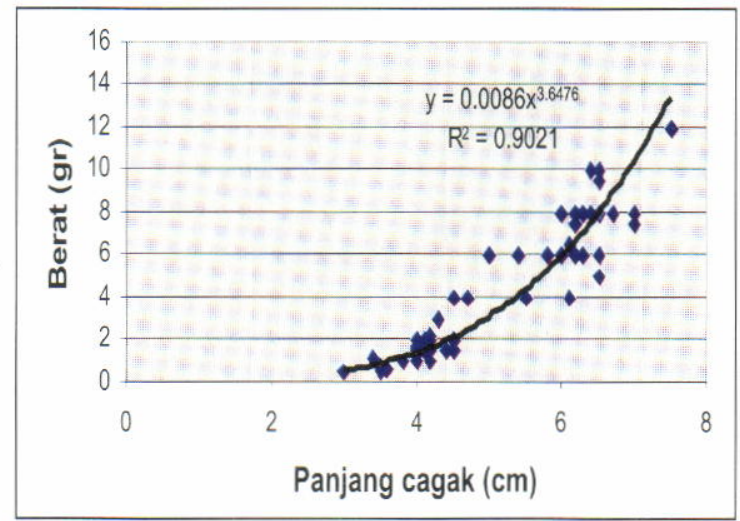

Gambar 9. Hubungan panjang bobot L. bindus.

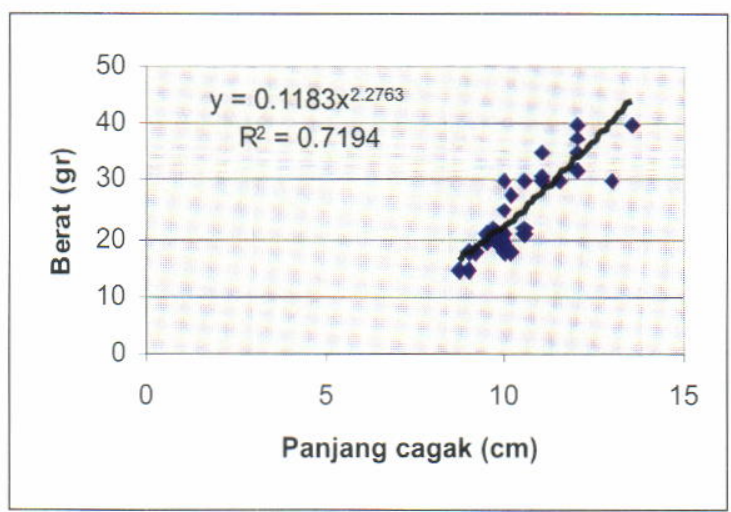

Gambar 11. Hubungan panjang bobot $T$. brevirostris. 
antara 15,1 sampai dengan $16 \mathrm{~cm}$, modus pada kisaran antara 12,1 sampai dengan $13 \mathrm{~cm}$, dengan rata-rata panjang 12,07 cm (Gambar 10).

Hubungan panjang bobot $T$. brevirostris menunjukkan pertumbuhan yang bersifat allometrik dengan nilai $r=0,848175$ (Gambar 11). Faktor kondisi $T$. brevirostris pada lokasi pengambilan contoh tidak baik $(1,21)$.

\section{KESIMPULAN DAN SARAN}

Perairan Ancol mendukung kehidupan ikan dan merupakan tempat asuhan beberapa ikan, tetapi kondisi tidak optimum. Keadaan ini dicerminkan dengan adanya juvenile ikan, ada indikasi pengelompokkan ukuran ikan lebih dari 1 kelompok umur, biomassa dan keanekaragaman rendah, serta faktor kondisi (kegemukan) rendah. Untuk mengoptimalkan daya dukung perairan Ancol terhadap kehidupan ikan, sebaiknya sanitasi lingkungan harus dilakukan secara menyeluruh baik daerah hilir maupun daerah hulu yang terkait dengan intake perairan Ancol.

\section{DAFTAR PUSTAKA}

Effendi, M. I. 1997. Biologi perikanan. Yayasan Pustaka. Jakarta.

Tarp, T. G. \& P. J. Kailola. 1984. Trawl fishes of Southern Indonesia and Northwestern Australia.

Whitehead, P. J. P. 1985. Species catalogue. clupeoid fishes of the world. Fisheries Synopsis. No.125. Vol.7. Part 1. United Nations Development Programme. Food and Agriculture Organization of The United Nations. Rome 1985.

Schuster, W. H. \& R. R. Djajadiredja. 1952. Local common name of Indonesian fishes. N. V. Penerbit W. Van hoeve. Bandung. 
